\title{
Effect of alkali and alkaline-earth cations on the neodymium environment in a rare-earth rich aluminoborosilicate glass
}

\author{
A. Quintas ${ }^{\text {a }}$, O. Majérus ${ }^{\mathrm{a}, *}$, M. Lenoir ${ }^{\mathrm{a}}$, D. Caurant ${ }^{\mathrm{a}}, \mathrm{K}_{\text {. Klementiev }}{ }^{\mathrm{b}}, \mathrm{A}^{\mathrm{A}}$ Webb ${ }^{\mathrm{b}}$ \\ ${ }^{a}$ Laboratoire de Chimie de la Matière Condensée de Paris, ENSCP, CNRS UMR 7574, \\ Ecole Nationale Supérieure de Chimie de Paris, 11 rue Pierre et Marie Curie, 75231 Paris cedex 05, France \\ ${ }^{\mathrm{b}}$ Hamburger Synchrotronstrahlungslabor HASYLAB, Notkestrasse 85, D-22607 Hamburg, Germany
}

Available online 26 October 2007

\begin{abstract}
The local structure around neodymium in an aluminoborosilicate glass bearing $3.6 \mathrm{~mol} \% \mathrm{Nd}_{2} \mathrm{O}_{3}$ is studied by optical absorption spectroscopy and EXAFS at the $\mathrm{Nd} \mathrm{L}_{\mathrm{III}}{ }^{-}$and $\mathrm{K}$-edges. The influence of the nature of alkalis $\left(\mathrm{M}^{+}=\mathrm{Li}^{+}, \mathrm{Na}^{+}, \mathrm{K}^{+}, \mathrm{Rb}^{+}, \mathrm{Cs}^{+}\right)$and alkalineearths $\left(\mathrm{M}^{2+}=\mathrm{Mg}^{2+}, \mathrm{Ca}^{2+}, \mathrm{Sr}^{2+}, \mathrm{Ba}^{2+}\right)$ on the coordination sphere of $\mathrm{Nd}^{3+}$ ions in the glass is particularly investigated. The $\mathrm{Nd}^{3+}$ sites are well-defined with $\mathrm{Nd}-\mathrm{O}$ mean distances of $2.46 \pm 0.03 \AA$, whatever the alkali and alkaline-earth ion type except $\mathrm{Li}^{+}$and $\mathrm{Mg}^{2+}$, for which glasses exhibit slightly more disordered $\mathrm{Nd}$ sites and longer $\mathrm{Nd}-\mathrm{O}$ distances $(2.49 \pm 0.03 \AA$ A $)$. Using bond valence considerations, a model is proposed for the $\mathrm{Nd}$ site, and consists in 7-8 non-bridging oxygens (NBO), every NBO being charge compensated by $2-3$ alkalis and alkaline-earths. The $\mathrm{Nd}-\mathrm{O}$ mean distance is adjusted according to the mean field strength of these cations, to avoid overbonding of the NBO's. A glass series with varying $\mathrm{Ca}^{2+} / \mathrm{Na}^{+}$concentration ratio shows that $\mathrm{Nd}^{3+}$ cations are able to maintain this average coordination site even at high alkaline-earth content.
\end{abstract}

(C) 2007 Elsevier B.V. All rights reserved.

PACS: $61.10 . \mathrm{Ht} ; 61.43 . \mathrm{Fs}$

Keywords: Synchrotron radiation; Optical spectroscopy; Borosilicates; Rare-earths in glasses; Short-range order; X-ray absorption

\section{Introduction}

A rare-earth rich aluminoborosilicate glass (about $10 \mathrm{wt} \%$ or $3.6 \mathrm{~mol} \% \mathrm{RE}_{2} \mathrm{O}_{3}$ ) has been designed for the immobilization of concentrated high-level nuclear waste (HLW) $[1,2]$. For the purpose of structural study, the composition of this glass has been restricted to seven oxides and is the following: (mol\%) $61.81 \mathrm{SiO}_{2}-3.05 \mathrm{Al}_{2} \mathrm{O}_{3}-8.94 \mathrm{~B}_{2} \mathrm{O}_{3}-$ $14.41 \mathrm{Na}_{2} \mathrm{O}-6.33 \mathrm{CaO}-1.90 \mathrm{ZrO}_{2}-3.56 \mathrm{RE}_{2} \mathrm{O}_{3}(\mathrm{RE}=\mathrm{Nd})$. Part of the rare-earth oxide simulates all the lanthanides and actinides occurring in HLW. The other part helps to incorporate the high amount of HLW and ensure good chemical durability and high glass transformation temperature. The present work is part of an extensive study of the

\footnotetext{
* Corresponding author. Tel.: +33 153737 936; fax: +33146347489. E-mail address: odile-majerus@enscp.fr (O. Majérus).
}

structure and thermal stability of this multicomponent glass [1-3] and focuses on the structural position of the rare-earth cation. A first glass series with increasing amount of $\mathrm{RE}_{2} \mathrm{O}_{3}$ has put in evidence the modifying role of the $\mathrm{RE}^{3+}$ ion in this glass [2]. Moreover, the optical absorption and X-ray absorption spectra of $\mathrm{RE}^{3+}$ $(\mathrm{RE}=\mathrm{Nd})$ resemble the spectra of $\mathrm{RE}^{3+}$ in simple alkali silicate glasses, while they are dissimilar to the spectra of alkali borates or rare-earth aluminate glasses. This fact is not surprising as the network is dominated by $\mathrm{SiO}_{4}$ tetrahedral units $(72 \%)$, and is suspected to homogeneously incorporate smaller amounts of $\mathrm{AlO}_{4}^{-}$units $(7 \%)$, and $\mathrm{BO}_{4}^{-}, \mathrm{BO}_{3}, \mathrm{BO}_{3}^{-}$units $(21 \%)$ [4]. At last, no Nd-Nd clustering at distances less than $4 \AA$ could be detected from $\mathrm{Nd}$ $\mathrm{L}_{\mathrm{III}}$-edge EXAFS in these studies [2].

Then, a structural model has emerged for the rare-earth cation in this glass, in which $\mathrm{RE}^{3+}$ enters a 
coordination sphere with several non-bridging oxygens (NBO, which are bonded to one network former and to several non-framework cations such as alkali or alkaline-earths) mainly connected to silicate units, and is surrounded by other modifying cations for its charge compensation. In the seven-oxide glass, these cations are $\mathrm{Na}^{+}$and $\mathrm{Ca}^{2+}$, but a great variety of neighboring cations must be assumed in the nuclear glass with complete composition. The $\mathrm{RE}^{3+}$, modifying cations and NBO's probably form depolymerized regions throughout the network, according to widely accepted models of glass structure [5,6], though their extent is matter of debate. To improve this model, we now investigate how the distribution of sites of the rare-earth ion may be dependent on the nature of the surrounding alkali and alkaline-earth ions. This investigation aims to explore the variety of $\mathrm{RE}^{3+}$ sites in the nuclear glass and reveal possible links to its chemical stability. Secondly, we expect to get a better insight into the details of the distribution of sites for $\mathrm{RE}^{3+}$ in the seven-oxide glass, i.e. the range of oxygen coordination, the mean parameters and distortion of the coordination sphere, and the identity of nearest neighbors.

Three glass series are studied: (1) A glass series with a varying $\mathrm{R}$ ratio, $R=100 \times[\mathrm{CaO}] /\left([\mathrm{CaO}] \times\left[\mathrm{Na}_{2} \mathrm{O}\right]\right)$; (2) $\mathrm{A}$ glass series with $R=30, \mathrm{M}^{2+}=\mathrm{Ca}^{2+}$ and $\mathrm{M}^{+}=\mathrm{Li}^{+}$, $\mathrm{Na}^{+}, \mathrm{K}^{+}, \mathrm{Rb}^{+}$or $\mathrm{Cs}^{+}$; (3) A glass series with $R=30$, $\mathrm{M}^{+}=\mathrm{Na}^{+}$and $\mathrm{M}^{2+}=\mathrm{Mg}^{2+}, \mathrm{Ca}^{2+}, \mathrm{Sr}^{2+}$ or $\mathrm{Ba}^{2+}$. The cation field strength is defined as $z / r^{2}$, where $z$ is the charge of the cation and $r$ its mean distance to oxygens. The three series cover a reasonably wide range of mean field strength (MFS) for the $\mathrm{M}^{+}$and $\mathrm{M}^{2+}$ cationic group, from 0.17 to 0.32 , as estimated from expected cation-oxygen distances [7] (Table 1). Then, the features of the $\mathrm{RE}^{3+}$ environment will be discussed in term of the mean field strength of the cationic neighbours.

\section{Experimental}

Three series of glasses have been prepared with the reference composition given in the introduction and $\mathrm{RE}=\mathrm{Nd}$. The first series has a varying $R=100 \times[\mathrm{CaO}] /$ $\left([\mathrm{CaO}]+\left[\mathrm{Na}_{2} \mathrm{O}\right]\right)$ ratio, with $R=0,15,30,50,70,85$. The corresponding glasses are referred to as «CaNaR». The two other series differ in the nature of the $\mathrm{M}^{+}$alkali ion $\left(« \mathrm{M}^{+} »\right.$ glasses), or of the $\mathrm{M}^{2+}$ alkaline-earth ion ( $« \mathrm{M}^{2+}{ }$ ) glasses), and have $R=30$ as in the seven-oxide reference glass. The oxide powders were melted at $1300^{\circ} \mathrm{C}$ for $3 \mathrm{~h}$, then heated at $1400{ }^{\circ} \mathrm{C}$ for $15 \mathrm{~min}$ and quenched in water. The glass frit was ground and melted again at $1300{ }^{\circ} \mathrm{C}$ for $2 \mathrm{~h}$ to ensure good homogeneity. The melt was finally cast into glass cylinders of $1.4 \mathrm{~cm}$ diameter, which were annealed at $T_{\mathrm{g}}+20^{\circ} \mathrm{C}$ for $2 \mathrm{~h}$, then cut and polished to get $\sim 1 \mathrm{~mm}$ thick plates for the optical absorption study. For all the glasses, composition was checked by chemical analysis (ICP-AES) and/or electron probe microanalysis (EPMA), and corresponds within $2 \mathrm{~mol} \%$ to the nominal composition.

Optical absorption spectroscopy was performed in transmission mode at $T \approx 10 \mathrm{~K}$, because at this temperature, only the lowest Stark level of the ${ }^{4} I_{9 / 2}$ ground state of $\mathrm{Nd}^{3+}$ is populated. Spectra were collected on the 400 $950 \mathrm{~nm}$ range with a double-beam CARY-5E spectrophotometer, using a spectral band width SBW of $0.6 \mathrm{~nm}$ (instrumental resolution function is thus $25 \mathrm{~cm}^{-1}$ at $500 \mathrm{~nm}$ ), a data interval DI of $0.2 \mathrm{~nm}$ and $1 \mathrm{~s}$ acquisition time.

X-ray absorption spectroscopy (XAS) has been carried out at the synchrotron HASYLAB (Hamburg, Germany), on the $\mathrm{E} 4$ beamline for the $\mathrm{Nd} \mathrm{L}_{\mathrm{III}}$-edge $(6212 \mathrm{eV}$ in these glasses) and on the high-energy $\mathrm{X} 1$ beamline for the $\mathrm{Nd} \mathrm{K}$ edge $(43592 \mathrm{eV}$ in these glasses). Appropriate quantities of glass powder to get about 1 order of magnitude of

Table 1

Position of the ${ }^{4} I_{9 / 2} \rightarrow{ }^{2} P_{1 / 2}$ optical absorption band and best-fit EXAFS parameters of the Nd-O coordination shell

\begin{tabular}{|c|c|c|c|c|c|c|c|}
\hline $\begin{array}{l}\text { Glass } \\
\text { sample }\end{array}$ & $\begin{array}{l}\mathrm{MFS} \\
\left(\AA^{-2}\right)\end{array}$ & $\begin{array}{l}{ }^{4} I_{9 / 2} \rightarrow{ }^{2} P_{1 / 2} \text { band center } \\
\left( \pm 4 \mathrm{~cm}^{-1}\right) \text { at } 10 \mathrm{~K}\end{array}$ & $\begin{array}{l}\text { XAS exp.: Edge and } \\
\text { Temperature }\end{array}$ & $\mathrm{dNd}-\mathrm{O}(\AA)$ & $\sigma^{2}\left(\AA^{2}\right)$ & $3^{\mathrm{d}}$ cum. $\left(\times 10^{-4} \AA^{3}\right)$ & $4^{\text {th }}$ cum. $\left(\times 10^{-5} \AA^{4}\right)$ \\
\hline $\mathrm{CaNa} 0$ & 0.17 & 23212 & $\mathrm{~L}_{\mathrm{III}}, 6 \mathrm{~K}$ & $2.447 \pm 0.010$ & $0.027 \pm 0.001$ & $14 \pm 5$ & $60 \pm 15$ \\
\hline $\mathrm{CaNa} 15$ & 0.20 & 23216 & $\mathrm{~L}_{\mathrm{III}}, 6 \mathrm{~K}$ & 2.456 & 0.0285 & 15 & 64 \\
\hline $\mathrm{CaNa} 30$ & 0.22 & 23222 & $\mathrm{~L}_{\mathrm{III}}, 6 \mathrm{~K}$ & 2.462 & 0.028 & 15 & 60 \\
\hline $\mathrm{CaNa} 50$ & 0.26 & 23228 & $\mathrm{~L}_{\mathrm{III}}, 6 \mathrm{~K}$ & 2.473 & 0.028 & 16 & 58 \\
\hline $\mathrm{CaNa} 70$ & 0.30 & 23230 & $\mathrm{~L}_{\mathrm{III}}, 6 \mathrm{~K}$ & 2.483 & 0.028 & 15.5 & 54 \\
\hline $\mathrm{CaNa} 85$ & 0.32 & 23233 & $\mathrm{~L}_{\mathrm{III}}, 6 \mathrm{~K}$ & 2.484 & 0.029 & 15 & 56 \\
\hline $\mathrm{Li}$ & 0.28 & 23238 & $\mathrm{~K}, 77 \mathrm{~K}$ & $2.48 \pm 0.015$ & $0.011 \pm 0.0025$ & $14 \pm 4$ & 0 \\
\hline $\mathrm{Na}(=\mathrm{CaNa} 30)$ & 0.22 & 23222 & $\mathrm{~K}, 77 \mathrm{~K}$ & 2.46 & 0.011 & 12 & 0 \\
\hline $\mathrm{K}$ & 0.19 & 23215 & $\mathrm{~K}, 77 \mathrm{~K}$ & 2.46 & 0.010 & 12 & 0 \\
\hline $\mathrm{Rb}$ & 0.18 & 23211 & $\mathrm{~K}, 77 \mathrm{~K}$ & 2.46 & 0.010 & 13 & 0 \\
\hline $\mathrm{Cs}$ & 0.17 & 23206 & $\mathrm{~L}_{\mathrm{III}}, 77 \mathrm{~K}$ & $2.45 \pm 0.02$ & $0.029 \pm 0.003$ & $18 \pm 8$ & $60 \pm 20$ \\
\hline $\mathrm{Mg}$ & 0.27 & 23234 & $\mathrm{~L}_{\mathrm{III}}, 77 \mathrm{~K}$ & 2.50 & 0.028 & 20 & 50 \\
\hline $\mathrm{Ca}(=\mathrm{CaNa} 30)$ & 0.22 & 23222 & $\mathrm{~L}_{\mathrm{III}}, 77 \mathrm{~K}$ & 2.46 & 0.028 & 13 & 65 \\
\hline $\mathrm{Sr}$ & 0.20 & 23222 & $\mathrm{~L}_{\mathrm{III}}, 77 \mathrm{~K}$ & 2.465 & 0.027 & 17 & 50 \\
\hline $\mathrm{Ba}$ & 0.19 & 23217 & $\mathrm{~L}_{\mathrm{III}}, 77 \mathrm{~K}$ & 2.47 & 0.027 & 17 & 50 \\
\hline
\end{tabular}

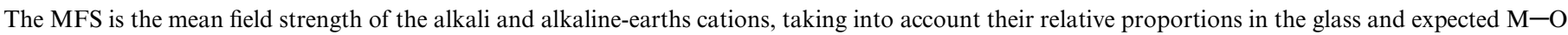

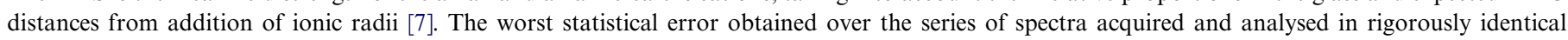
conditions, is indicated (three series). 
absorption at the edge, were mixed with cellulose and pressed into pellets. Spectra were acquired in transmission mode at $T=6 \mathrm{~K}$ (He cryostat) or $T=77 \mathrm{~K}\left(\mathrm{~N}_{2}\right.$ cryostat) in order to reduce thermal broadening. $\mathrm{Si}(111)$ and $\mathrm{Si}(511)$ monochromators were used for the $\mathrm{L}_{\mathrm{III}}{ }^{-}$and $\mathrm{K}$ edges respectively, and X-ray intensity was measured by ion chambers. Two to three scans were acquired for each sample. $\mathrm{Ca}_{2} \mathrm{Nd}_{8}\left(\mathrm{SiO}_{4}\right)_{6} \mathrm{O}_{2}$ and $\mathrm{Nd}_{2} \mathrm{Si}_{2} \mathrm{O}_{7}$ ceramics were also measured as references. EXAFS oscillations $(\chi(k))$ were extracted from the normalized absorption spectra using a spline in the ATHENA software [7]. The $k^{3}$ weighted $\chi(k)$ was Fourier transformed on the $3-9 \AA^{-1}$ range for $\mathrm{L}_{\mathrm{III}}$-edge, or the $3-12 \AA^{-1}$ range for $\mathrm{K}$-edge. The signal corresponding to the coordination shell $(\mathrm{O}$ neighbours) was fitted in $r$-space between 1.4 and $2.4 \AA$ with the ARTEMIS software [8]. Given the low resolution obtained from the spectra $\left(0.17 \AA\right.$ and $0.13 \AA$ for $\mathrm{L}_{\mathrm{III}}$ and $\mathrm{K}$-edges respectively), a single oxygen contribution was supposed. Single scattering $\mathrm{Nd}-\mathrm{O}$ phase and amplitude functions were calculated by FEFF6, on the basis of a Nd-O distance of $2.46 \AA . \Delta E_{0}$ and amplitudes $\left(\mathrm{N} \times \mathrm{S}_{0}^{2}\right)$ were fixed at the following values: $\Delta E_{0}=+5 \mathrm{eV}$ and $\mathrm{N} \times \mathrm{S} 02=8$ for the $\mathrm{L}_{\mathrm{III}}$-edge spectra, and $\Delta E_{0}=+3 \mathrm{eV}$ and $\mathrm{N} \times \mathrm{S} 02=5$ for the K-edge spectra. The noticeable difference between the amplitudes is attributed to the broadening due to the short core-hole lifetime at the K-edge. The distribution of $\mathrm{Nd}-\mathrm{O}$ distances was modelled with four parameters: the mean $\mathrm{Nd}-\mathrm{O}$ distance $\mathrm{dNd}-\mathrm{O}$, the Debye-Waller factor $\sigma^{2}$ and the third and fourth cumulants [9]. Statistical errors are evaluated from the noise level of the data, through statistical analysis provided by the ARTEMIS software [8], while systematic error is minimized by checking that the single scattering $\mathrm{Nd}-\mathrm{O}$ amplitude and phase functions correctly fit the spectra of the above mentioned crystalline references. Statistical errors differ according to the number of accumulated scans (2 or 3 ), the temperature and the edge.

\section{Results}

\subsection{Optical absorption spectroscopy}

At low temperature, the ${ }^{4} I_{9 / 2} \rightarrow{ }^{2} P_{1 / 2}$ transition of $\mathrm{Nd}^{3+}$ at about $23220 \mathrm{~cm}^{-1}$ consists in a single band since the ${ }^{2} P_{1 / 2}$ level is not split by the crystal field. The profile of this band reflects the distribution of sites of $\mathrm{Nd}^{3+}$ ions in the glass. This absorption band is shown in Fig. 1 for the $\mathrm{CaNaR}$ glass series. This band can be fitted by a single Gaussian with a half-height width of about $110 \mathrm{~cm}^{-1}$ for all glasses of the three series. Slight asymmetry can be observed on the low-energy side of the band of some samples, and is due to minor population of the second Stark level of the ${ }^{4} I_{9 / 2}$ ground state («hot band region», [10]). Furthermore, the central position of the band increases in energy with the increase of the mean field strength (Table 1 and Fig. 1). This shift is greatest in the series with varying alkali type, from $23206 \mathrm{~cm}^{-1}$ for the Cs glass

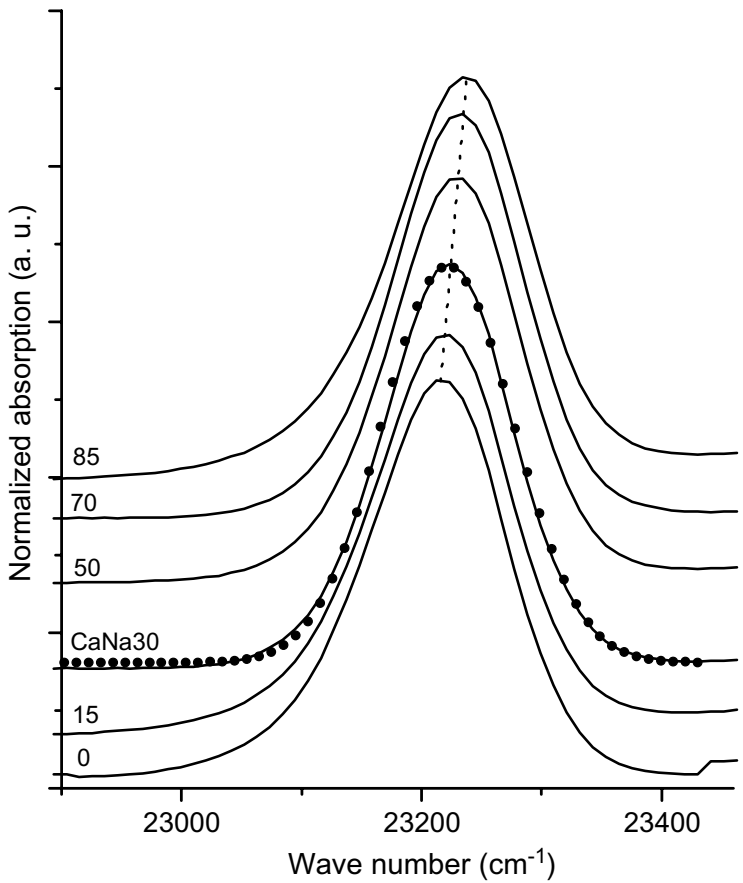

Fig. $1 .{ }^{4} I_{9 / 2} \rightarrow{ }^{2} P_{1 / 2}$ optical absorption band $(T=10 \mathrm{~K})$ in glasses of the $\mathrm{CaNaR}$ series (lines), and an example of Gaussian fit (dots). The corresponding $R$ values are given in the figure. Spectra have been normalized to sample thickness.

$(\mathrm{MFS}=0.17)$ to $23240 \mathrm{~cm}^{-1}$ for the Li glass $(\mathrm{MFS}=$ 0.28 ). Origin of this shift lays in the nephelauxetic effect, according to which the expansion of the partly filled f-shell towards the oxygen ligands, caused by the covalency of the $\mathrm{RE}-\mathrm{O}$ bonds, reduces the coulombic electron-electron interaction within the $4 \mathrm{f}$ shell, and consequently lowers the energy of the excited ${ }^{2 \mathrm{~S}+1} \mathrm{~L}_{\mathrm{J}}$ states relatively to the ground state.

An other interesting band is the ${ }^{4} I_{9 / 2} \rightarrow{ }^{4} G_{5 / 2},{ }^{2} G_{7 / 2}$ transition which occurs at about $17250 \mathrm{~cm}^{-1}$ and is referred to as the «hypersensitive band» in the literature $[12,13]$. This transition is shown in Fig. 2 for several glasses. With decreasing MFS, shoulders progressively appear on the low-energy side of the two main bands, denoting a change in the relative positions of the Stark levels. This evolution is consistent with the literature [12] and reveals changes in the symmetry of the crystal field around $\mathrm{Nd}^{3+}$. The most significant effect again happens in the glass series with varying alkali type.

\subsection{Nd $L_{I I I}$-edge and K-edge EXAFS}

A representative $\mathrm{K}$-edge $k^{3}$-weighted EXAFS function is presented in Fig. 3(a), while Fig. 3(b) presents the magnitude of the Fourier transforms of these functions (on 3 $12 \AA^{-1}$ ) for the alkali glass series. Results of the one-shell fits are reported in Table 1 for all glasses. Although measurement at the $\mathrm{K}$-edge allows data collection over a wide energy range (more than $1400 \mathrm{eV}$, i.e. $18 \AA^{-1}$ ), we found that the oscillations had damped before $14 \AA^{-1}$, because in these complex glasses, the static and chemical disorder 


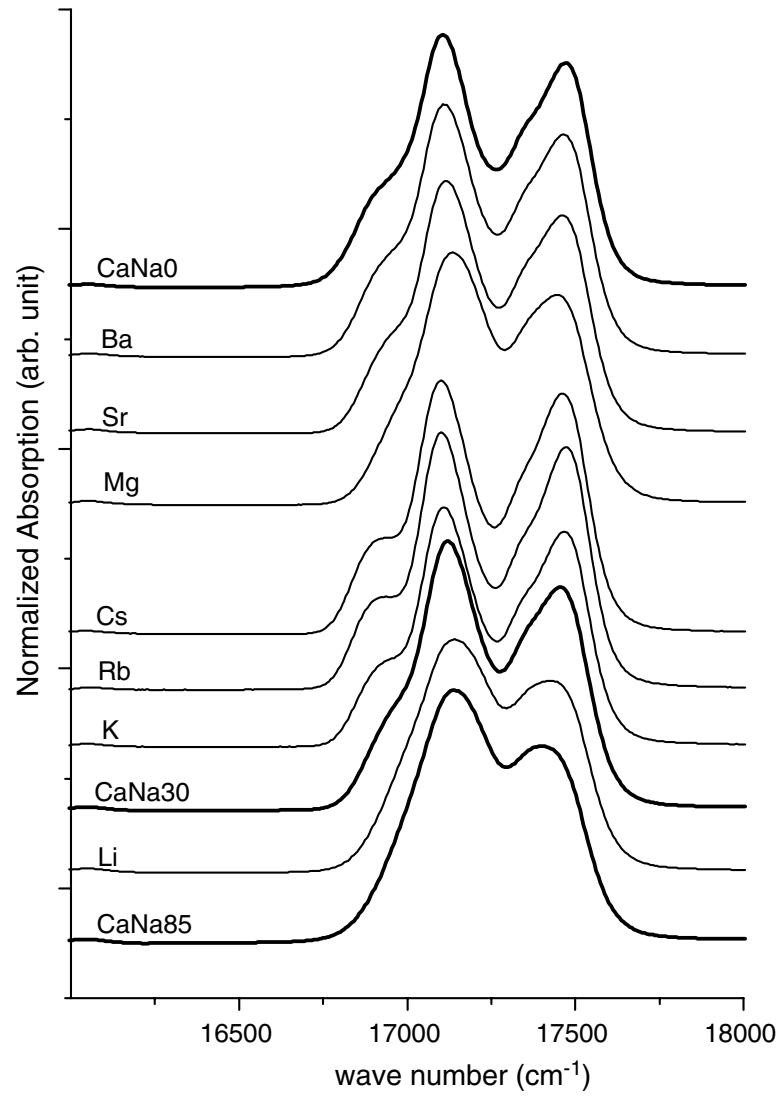

Fig. 2. ${ }^{4} I_{9 / 2} \rightarrow{ }^{4} G_{5 / 2}, \quad{ }^{4} G_{7 / 2}$ hypersensitive optical absorption band $(T=10 \mathrm{~K})$ in selected glasses of the three glass series. * Shoulders on the low-energy side of the two main bands. Spectra have been normalized to sample thickness.

beyond the oxygen coordination shell is very large and prevents efficient scattering of the electronic waves. Moreover, the short core-hole lifetime at the K-edge induces a constant loss of resolution in energy space, equivalent to a broadening mostly affecting the low $k$-range [14], where oxygen contribution is highest. As a matter of fact, the $\mathrm{K}$-edge did not provide much more information than the $\mathrm{L}_{\mathrm{III}}$-edge about these glasses.

The $\mathrm{Nd}-\mathrm{O}$ mean distance exhibits a nearly regular increase with the mean field strength of the alkali and alkaline-earth cations, from $2.45 \pm 0.02 \AA$ for the $\mathrm{CaNa} 0$ and Cs glasses (MFS $=0.17$ ), to $2.50 \pm 0.02 \AA$ for the $\mathrm{Mg}$ glass $(\mathrm{MFS}=0.27) . \mathrm{Li}$ glass and $\mathrm{CaNa} 85$ glass with $\mathrm{MFS}=0.28$ and 0.32 respectively have a mean $\mathrm{Nd}-\mathrm{O}$ distance of $2.48 \pm 0.015$ A.

The Debye-Waller values correspond to the r-space resolution induced by the limited range of the k-Fourier transform. At the $\mathrm{L}_{\mathrm{III}}$-edge indeed, $k_{\max }=9 \AA^{-1}$ in the FT, gives resolution $\Delta r=\pi /\left(2 \times \Delta \mathrm{k}_{\max }\right)=0.17 \AA$, and thus $(\Delta r)^{2}=0.0289 \AA^{2} \approx \sigma^{2}$. At the K-edge, $k_{\max }=$ $12 \AA^{-1}$ gives $\Delta \mathrm{r}=0.13 \AA$ and $(\Delta r)^{2}=0.017 \AA^{2}$, close to $\sigma^{2}$ given the uncertainty on the amplitudes at this edge. Thus, the distribution of $\mathrm{Nd}-\mathrm{O}$ distances is less than $0.13 \AA$ in all glasses, depicting an essentially regular site.
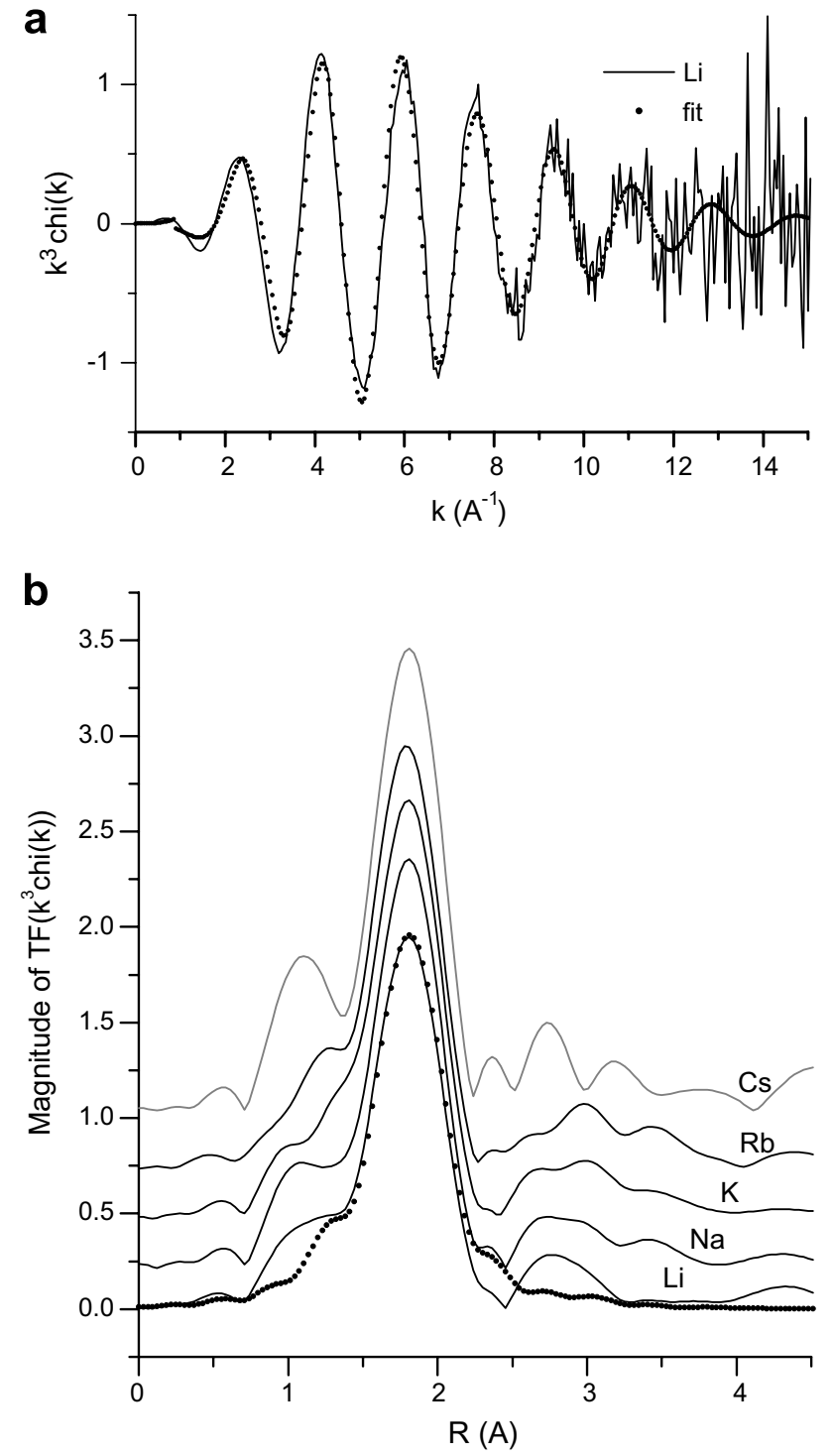

Fig. 3. (a) $k^{3}$-weighted $\mathrm{Nd} \mathrm{K}$-edge EXAFS function of the Li glass and one oxygen shell fit (dots). (b) Magnitude of Fourier transforms of the $k^{3}$-weighted Nd K-edge EXAFS functions for the $\mathrm{M}^{+}$glass series and one oxygen shell fit (dots). The Cs glass TF is lighted as the spectrum was noisy.

The damping of the EXAFS oscillations slightly increases with the $\mathrm{R}$ ratio within the $\mathrm{CaNaR}$ series, as evidenced by visual comparison of the spectra (not shown). This is accounted for by a slight increase in the $\sigma^{2}$ factor from $0.027 \pm 0.001 \AA^{2}$ to $0.029 \pm 0.001 \AA^{2}$, and a slight decrease of the fourth cumulant, from $(60 \pm 15) \times 10^{-5}$ $\AA^{4}$ to $(56 \pm 15) \times 10^{-5} \AA^{4}$. Indeed, the relative error is expected to be smaller than the absolute error within this series, since these spectra have been acquired and analysed rigourously in the same conditions. This reveals a progressive disordering of the coordination shell, characterized by a slightly wider spread of distances. Similarly, $\mathrm{Nd}$ has a more disordered shell in the Li glass and in the Mg glass, with respect to the rest of the alkali and alkaline-earth series for which no measurable variation of the $\sigma^{2}$ and 
cumulants parameters occurs. This slight distortion of individual sites may be responsible for the changes in crystal field symmetry observed by optical absorption spectroscopy. However, it is so small (at the limit of being measured by EXAFS), that the $\mathrm{Nd}$ sites may be considered well-defined in these glasses.

At last, the EXAFS data bear a signal from the second neighbors shell, as evidenced by the comparison between the spectra in Fig. 3(b). The contribution from second neighbors, occuring at a pseudo-distance of about $3 \AA$, is enlarged and less and less visible from $\mathrm{Li}$ to Cs. In the Li glass, this contribution may be mainly due to network atoms $(\mathrm{Si}, \mathrm{B}$, $\mathrm{Al}, \mathrm{O}$ ), since the $\mathrm{X}$-ray scattering amplitude of $\mathrm{Li}$ is weak. In other glasses, the contribution of alkali in the second neighbor signal increases with their atomic number. The progressive disappearance of this signal then reflects a high disordering of the alkali ions around $\mathrm{Nd}$.

\section{Discussion}

\subsection{Implications from optical absorption spectroscopy}

From the Gaussian profile of the ${ }^{4} I_{9 / 2} \rightarrow{ }^{2} P_{1 / 2}$ absorption band, we infer that the distribution of sites occupied by $\mathrm{Nd}^{3+}$ is unique and its broadening does not markedly depend on the alkali or alkaline-earth ion type. The ${ }^{4} I_{9 / 2} \rightarrow{ }^{2} P_{1 / 2}$ transition of $\mathrm{Nd}^{3+}$ occurs at $23260 \mathrm{~cm}^{-1}$ and above 23240 $\mathrm{cm}^{-1}$ in aluminate and borate environments respectively $[1,10]$. The transition centre at about $23220 \mathrm{~cm}^{-1}$ in the present glasses precludes any significant contribution of these environments in the $\mathrm{Nd}^{3+}$ distribution of sites, contrary to the results in other aluminoborosilicate glass compositions more enriched in $\mathrm{Al}_{2} \mathrm{O}_{3}$ and $\mathrm{B}_{2} \mathrm{O}_{3}$ [11].

In the sodium borate glass system, in which $\mathrm{Nd}^{3+}$ either enters sites dominated by bridging oxygens (low sodium content), or sites dominated by non-bridging oxygens (high sodium content), the position of the $\mathrm{Nd}^{3+}{ }^{4} I_{9 / 2} \rightarrow{ }^{2} P_{1 / 2}$ transition shifts over a range of about $150 \mathrm{~cm}^{-1}$ [10]. In our glasses, only the nature of the alkali/akaline-earth cations is varied, which provokes limited variation of the polymerization degree or NBO content of the network. Thus, if the network remains homogeneous, the average $\mathrm{NBO} / \mathrm{BO}$ ratio around $\mathrm{Nd}^{3+}$ ions is not expected to change very much. An interpretation of the $34 \mathrm{~cm}^{-1}$ high energy shift of the ${ }^{4} I_{9 / 2} \rightarrow{ }^{2} P_{1 / 2}$ transition observed in our data, is that the cationic neighbors with high field strength polarize the negative charge of the NBO ligands, which thus interact less covalently with $\mathrm{Nd}^{3+}$ ions. As a consequence the $\mathrm{Nd}-\mathrm{O}$ distance is longer, as demonstrated by EXAFS. Interestingly, the highest energy shift takes place within the glass series with varying alkali type, and not within the series with varying $\mathrm{Ca}^{2+} / \mathrm{Na}^{+}$ratio which however covers the largest MFS range (compare the extreme values of each series in Table 1). In the CaNaR glass series, where $\mathrm{Na}^{+}$are progressively replaced by $\mathrm{Ca}^{2+}$, the $\mathrm{Na}^{+}$ions may preferently stay in the vicinity of $\mathrm{Nd}^{3+}$, so that the bond covalency does not change with the MFS as abruptely as in the $\mathrm{M}^{+}$glass series.

\subsection{Bond valence model of $N d$ sites inferred from the EXAFS $\mathrm{Nd}-\mathrm{O}$ mean distance}

Bond valences in oxides can be calculated according to Brese and O'Keeffe empirical relationship [15]:

$\mathrm{s}=\exp \left(\left(R_{0}-R\right) / 0.37\right)$

where $R_{0}$ is tabulated for every ion after examination of a number of crystal structures $\left(R_{0}=2.117 \AA\right.$ for $\left.\mathrm{Nd}^{3+}\right)$, and $\mathrm{R}$ is the distance between ion and oxygen. For a given ion engaged in bonds to oxygens, the sum of bond valences

Table 2

Bond valences $\mathrm{s}(\mathrm{Nd}-\mathrm{O})$ in aluminoborosilicate glasses of this study (from EXAFS $\mathrm{Nd}-\mathrm{O}$ distances), expected bond valences $\mathrm{s}(\mathrm{M}-\mathrm{O})$ for alkali and alkaline-earth ions (distances correspond to the addition of ionic radii, [6]) and proposed model for Nd and NBO coordination

\begin{tabular}{lllllll}
\hline Glass and & $\mathrm{CN}[6]$ & $\mathrm{dM}-\mathrm{O}(\AA,[6])$ & $\mathrm{s}(\mathrm{M}-\mathrm{O})[6]$ & $\mathrm{dNd}-\mathrm{O}$ in $\AA \quad \mathrm{s}(\mathrm{Nd}-\mathrm{O})$ & Bond valence model
\end{tabular} Cation type $\mathrm{M} \quad$ for NBO and total number to NBO ${ }^{\mathrm{b}}$

Li glass

$\begin{array}{lll}\mathrm{Li}^{+} & 4 & 1.99 \\ \mathrm{Ca}^{2+} & 6 & 2.36\end{array}$

$\begin{array}{lll}\mathrm{Li} & 4 & 1.99 \\ \mathrm{Ca}^{2+} & 6 & 2.36\end{array}$

$99-0.27$

$0.27 \quad 2.48$

bond valence $^{\mathrm{a}}$

Na glass (=CaNa30)

$\mathrm{Na}^{+} \quad 6 \quad 2.38$

$\mathrm{Ca}^{2+}$

\subsection{8}

0.35

0.375

$2 \mathrm{Li}^{+}$

2.01

$1 \mathrm{Li}^{+}$and $1 \mathrm{Ca}^{2+}$

2.09

Cs glass

$\mathrm{Cs}^{+}$

$\mathrm{Ca}^{2+}$

$8 \quad 3.10$

0.21

0.35

2.46

0.40

$2 \mathrm{Na}^{+}$

$1.92 \quad 7.5$

$1 \mathrm{Na}^{+}$and $1 \mathrm{Ca}^{2+} \quad 2.06$

$0.16 \quad 2.45$

0.41

$3 \mathrm{Cs}^{+}$

1.99

0.35

$1 \mathrm{Cs}^{+}$and $1 \mathrm{Ca}^{2+}$

2.02

Mg glass

$\mathrm{Na}^{+}$
$\mathrm{Mg}^{2+}$

$\begin{array}{lll}6 & 2.38 & 0.21\end{array}$

2.50

0.355

$1 \mathrm{Na}^{+}$and $1[6] \mathrm{Mg}^{2+} \quad 2.01$ $1[4] \mathrm{Mg}^{2+}$ 1.98

8.4

${ }^{\text {a }}$ Calculation with $\mathrm{Si}-\mathrm{NBO}$ bond valence equal to 1.1 . Example of total bond valence (BV) calculation for a $\mathrm{NBO}$ bonded to $\mathrm{Si}^{4+}, \mathrm{Nd}^{3+}$ and two $\mathrm{Li}^{+}$: $\mathrm{BV}=1.1+0.375+2 \times 0.27=2.01$.

${ }^{\mathrm{b}}$ Calculated to achieve a total bond valence of 3 for $\mathrm{Nd}:$ mean $\mathrm{CN}=3 / \mathrm{s}(\mathrm{Nd}-\mathrm{O})$. 
must equal the ionic charge, and inversely, for given oxygen the sum of bond valences must be close to 2 . Table 2 gives examples of bond valence calculation in the aluminoborosilicate glasses of this study. All $\mathrm{Nd}-\mathrm{O}$ mean distances, experimentally determined from EXAFS, are in agreement with the following model. $\mathrm{Nd}^{3+}$ ions are coordinated to 7-8 NBO's in average, whatever the type of alkali and alkaline-earth ions in the composition, and the NBO negative charges are compensated by 2-3 alkalis, or 1 alkali and 1 alkaline-earth per NBO. Note that the 7-8 coordination number is consistent with the EXAFS $\mathrm{N} \times \mathrm{S}_{0}^{2}$ parameter, which was fixed at 8 for the $\mathrm{L}_{\mathrm{III}}$-edge. The $\mathrm{Nd}-\mathrm{O}$ mean distance adjusts itself in order that the NBO's are not over- or underbonded. This is an average picture and distorted sites exist with spread $\mathrm{Nd}-\mathrm{O}$ distances, forming the unique distribution of sites mirrorred in optical and $\mathrm{X}$-ray absorption spectra.

\subsection{Distortion of individual Nd sites according to the nature of alkali and alkaline-earth neighbors}

The symmetry of the average individual site changes when increasing the $\mathrm{R}$ ratio or inserting $\mathrm{Li}^{+}$or $\mathrm{Mg}^{2+}$, as demonstrated by the changes in Stark level relative positions $\left({ }^{4} I_{9 / 2} \rightarrow{ }^{4} G_{5 / 2},{ }^{2} G_{7 / 2}\right.$ transition). EXAFS spectroscopy reveals that it corresponds to a slight distortion of the $\mathrm{Nd}$ site (increase of the $\sigma^{2}$ value in the $\mathrm{CaNaR}$ series), but the extent of this distortion is at the limit of being measured with the experimental conditions of this study: the $\sigma^{2}$ and fourth cumulant variations stay within $0.003 \AA^{2}$ and $15 \times 10^{-5} \AA^{4}$ respectively.

In the CaNaR glasses with $R=70$ and $R=85, \mathrm{Ca}^{2+}$ ions are in greater number than $\mathrm{Na}^{+}$ions. The $\mathrm{Nd}-\mathrm{O}$ mean distance is $2.48 \AA \pm 0.01 \AA$ from EXAFS, so that the total bond valence on the $\mathrm{Si}-(\mathrm{NBO})-\mathrm{Nd}$ oxygen is $\mathrm{BV}=1.1 \quad$ (from $\mathrm{Si}-\mathrm{O}$ bond) $+0.37 \quad$ (from $\mathrm{Nd}-\mathrm{O}$ bond) $=1.47$. The excess negative charge on this NBO is compensated by an intermediate situation between one $\mathrm{Ca}^{2+}$ at $2.36 \AA(\mathrm{BV}=1.47+0.35=1.82$, underbonding $)$ and $2 \mathrm{Ca}^{2+}$ at $2.36 \AA(\mathrm{BV}=1.47+2 \times 0.35=2.17$, overbonding). Both the $\mathrm{Ca}-\mathrm{O}$ and $\mathrm{Nd}-\mathrm{O}$ bond distances adjust in order to provide appropriate NBO charge compensation. This may explain the wider spread of $\mathrm{Nd}-\mathrm{O}$ distances of these sites, as observed by EXAFS, and possibly the preferential compensation by $\mathrm{Na}^{+}$which was suggested from optical absorption spectroscopy.

As a whole, these results confirm that $\mathrm{Nd}$ sites are well defined in these aluminoborosilicate glasses, in agreement with previous findings on other complex silicate glasses [16]. Fig. 4 supports this view: the $\mathrm{Nd}-\mathrm{O}$ mean distances from EXAFS are plotted with respect to the ${ }^{4} I_{9 / 2} \rightarrow{ }^{2} P_{1 / 2}$ band center from optical absorption spectroscopy, for all glasses of the three series. The correlation is nearly linear within error bars (except for the Mg glass), which means that the variation of $\mathrm{Nd}-\mathrm{O}$ bond covalency in these glasses, is essentially determined by the variation of $\mathrm{Nd}-\mathrm{O}$

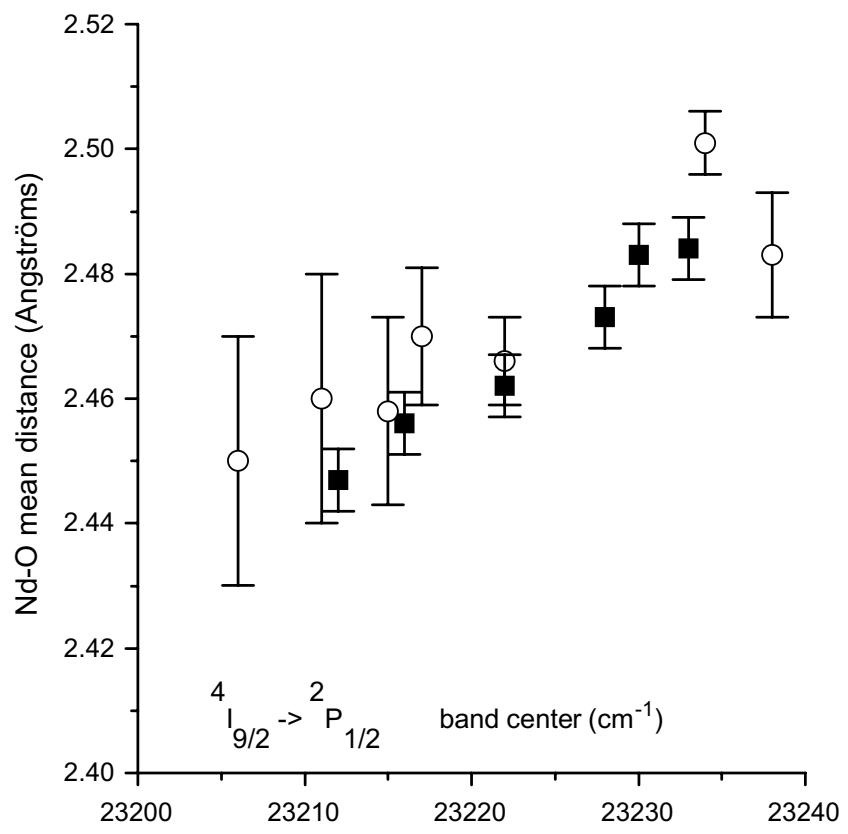

Fig. 4. Correlation between $\mathrm{Nd}-\mathrm{O}$ mean distance from EXAFS and ${ }^{4} I_{9 / 2} \rightarrow{ }^{2} P_{1 / 2}$ band center in the aluminoborosilicate glasses with different alkali or alkaline-earth types (open circles) or varying $\mathrm{CaO} /\left(\mathrm{Na}_{2} \mathrm{O}+\mathrm{CaO}\right)$ ratio (closed squares).

mean distance. No significant change in site symmetry happens.

\section{Conclusion}

Optical absorption and EXAFS spectroscopies of $\mathrm{Nd}^{3+}$ in a wide range of aluminoborosilicate glasses, with identical network composition and varying alkali/alkaline-earth ion types $\left(\mathrm{M}^{2+}=30 \%\right.$ of total $\mathrm{M}^{2+}+\mathrm{M}^{+}$ ions), put in evidence that the $\mathrm{Nd}^{3+}$ sites are well-defined and similar in all glasses. The neodymium ion is surrounded by $7-8$ non bridging oxygens, and the negative charge of the coordination shell is compensated by 2 to 3 alkalis, or 1 alkali and 1 alkaline-earth ions, per $\mathrm{NBO}$. The $\mathrm{Nd}-\mathrm{O}$ mean distance increases by $0.05 \pm 0.02 \AA$, when the field strength of the alkali and alkaline-earth cations increases. The $\mathrm{Nd}-\mathrm{O}$ distribution of distances is inferior to $0.13 \AA$ and no dependency on the alkali or alkaline-earth nature is measurable, except for the high field strength cations $\mathrm{Li}^{+}$and $\mathrm{Mg}^{2+}$. In these latter glasses indeed, a slight disordering of the oxygen coordination shell is noticed by EXAFS. The present results show that $\mathrm{Nd}^{3+}$ ions are able to impose their most favourable environment in these glasses, whatever the nature of the other modifying cations.

When increasing the $\mathrm{Ca}^{2+} / \mathrm{Na}^{+}$concentration ratio, the $\mathrm{Nd}-\mathrm{O}$ shell becomes slightly distorted. However, the $\mathrm{Nd}-\mathrm{O}$ mean distance does not increase very much, suggesting that $\mathrm{Nd}^{3+}$ ions maintain their preferred environment even at high alkaline-earth content, possibly thanks to preferential charge compensation by $\mathrm{Na}^{+}$ions. 


\section{Acknowledgments}

We would like to acknowledge HASYLAB's members for their help and availability during EXAFS experiments.

\section{References}

[1] I. Bardez, PhD thesis of University Pierre et Marie Curie, Paris, France, 2004, p. 244.

[2] I. Bardez, D. Caurant, J.-L. Dussossoy, P. Loiseau, C. Gervais, F. Ribot, D.R. Neuville, N. Baffier, C. Fillet, Nucl. Sci. Eng. 153 (2006) 272.

[3] I. Bardez, D. Caurant, P. Loiseau, N. Baffier, J.-L. Dussossoy, C. Gervais, F. Ribot, D.R. Neuville, Phys. Chem. Glasses 46 (4) (2005) 320.

[4] A. Quintas, T. Charpentier, O. Majérus, D. Caurant, J.-L. Dussossoy, P. Vermaut, Appl. Mag. Res., submitted for publication.

[5] G.N. Greaves, A. Fontaine, P. Lagarde, D. Raoux, S.J. Gurman, Nature 293 (1981) 611.
[6] P. Jund, W. Kob, R. Jullien, Phys. Rev. B 64 (2001) 134303.

[7] G.E. Brown Jr., F. Farges, G. Calas, in: J.F. Stebbins, P.F. McMillan, D.B. Dingwell (Eds.), Structure, Dynamics and Properties of Silicate melts, Reviews in Mineralogy, vol. 32, The Mineralogical Society of America, Washington D.C., 1995, p. 615.

[8] B. Ravel, M. Newville, J. Synchrotron Rad. 12 (4) (2005) 537.

[9] G. Dalba, P. Fornasini, F. Rocca, Phys. Rev. B 47 (14) (1993) 8502.

[10] K. Gatterer, G. Pucker, H.P. Fritzer, S. Arafa, J. Non-Cryst. Solids 176 (1994) 237.

[11] H. Li, L. Li, J.D. Vienna, M. Qian, Z. Wang, J.G. darab, D.K. Peeler, J. Non-Cryst. Solids 278 (2000) 35.

[12] A.A. Dymnikov, A.K. Przhevuskii, J. Non-Cryst. Solids 215 (1997) 83.

[13] K. Gatterer, G. Pucker, W. Jantscher, H.P. Fritzer, S. Arafa, J. NonCryst. Solids 231 (1998) 189.

[14] M. Borowski, D.T. Bowron, S.D. Panfilis, J. Synchrotron Rad. 6 (1999) 179.

[15] N.E. Brese, M. O'Keeffe, Acta Cryst. B 47 (1991) 192.

[16] T.F. Belliveau, D.J. Simkin, J. Non-Cryst. Solids 110 (1989) 127. 